\title{
Assessment of the impact of pharmacist-led face-to-face counselling on HIV/ AIDS among school \& college going students, and infected patients in south India
}

\author{
Sai Krishna Gudi ${ }^{\mathrm{a}, *}$, Manik Chhabra ${ }^{\mathrm{b}}$, Muhammed Rashid ${ }^{\mathrm{c}}$ \\ ${ }^{a}$ Department of Pharmacy, Rady Faculty of Health Sciences, University of Manitoba, Canada \\ ${ }^{\mathrm{b}}$ Department of Pharmacy Practice, Indo-Soviet Friendship College of Pharmacy, Moga, Punjab, India \\ ${ }^{\mathrm{c}}$ Department of Pharmacy Practice, Sri Adichunchanagiri College of Pharmacy, Adichunchanagiri University, B G Nagara, Karnataka, India
}

A R T I C L E I N F O

\section{Keywords:}

HIV/AIDS

Counselling

Pharmacist

Students

Patients

India

\begin{abstract}
A B S T R A C T
Problem considered: Over the past decade HIV/AIDS infection has tremendously increased among young people aged 15-24 years in the developing countries like India. By keeping this in mind, pharmacist counselling could be an essential asset that has been associated with improved health outcomes among public and infected patients as well.

Aim: To assess the impact of pharmacist-led counselling on HIV/AIDS among school \& college going students and infected patients.

Methods: A prospective intervention survey was conducted by using the simple random sampling technique. A total of 509 participants were sampled i.e., post-secondary school students (98), college students (364), and infected patients (47) respectively and interviewed by the student pharmacist using a pre-designed, semistructured questionnaire to assess their knowledge regarding HIV/AIDS pre and post-test respectively. Verbal consent from all the participants was obtained before initiating the study. Responses were scored, analyzed and mean score and percentage were used to determine the level of knowledge pre and post-test.

Results: Of the total 509 survey participants, 246 (48.3\%) were males, and 263 (51.7\%) were females with a mean age and SD of 24.59 years \pm 0.54 . The study results noticed that the study participants, especially school students and infected patients were not attentive and conscious about the HIV/AIDS.

Conclusion: The study results infer that there is an immense need for health education and prevention awareness camps for HIV/AIDS among school \& college going students as well as the infected patients in south India.
\end{abstract}

\section{Introduction}

HIV/AIDS is the abbreviated form for Human Immunodeficiency Virus and Acquired Immune Deficiency Syndrome. ${ }^{1}$ HIV is a virus which eventually causes AIDS, ${ }^{2}$ while previous names for this virus include human T-lymphotropic virus-III (HTLV-III), lymphadenopathyassociated virus (LAV), or AIDS-associated retrovirus (ARV). ${ }^{3}$ As the name itself denotes, it is a condition caused by a deficiency in the body's immune system. It is addressed as a syndrome as it encompasses a pattern of different symptoms with varied manifestations in different cases and it is an acquired infectious disease caused by a virus which can transmit from person to person through a variety of routes. ${ }^{4}$ Transmission of AIDS essentially requires exchange of body fluid such as semen, vaginal secretions, blood, and breast milk containing the virus. ${ }^{5}$ The other risk factors for causing AIDS are Homosexuality,
Heterosexuality, Mother-to-baby, Intravenous drug abuse, Transmission of blood, organ, and tissue transplants, etc. from the infected person. As of today, there is no vaccine or cure for AIDS, the only option available is to prevent it by practicing safety measures. ${ }^{4,5}$

Among the top HIV epidemic countries in the world, India tops the list with the third position accounting for 2.1 million people living with HIV in 2017. According to the UNAIDS, HIV/AIDS related deaths have notably increased to 88,000 from 80,000 in India in $2017 .^{6}$ Though knowledge regarding HIV/AIDS is an integral aspect of its prevention, a very few studies have examined the knowledge about HIV/AIDS among the students across the world. ${ }^{7-14}$ However, it has not been expeditiously examined among secondary school students and infected patients in India. ${ }^{15}$ Thus, the results of the majority studies mentioned above showed poor knowledge about HIV/AIDS among students. Therefore, this cross-sectional study attempted to identify the

\footnotetext{
* Corresponding author.

E-mail address: sknanu06@gmail.com (S.K. Gudi).
} 
knowledge related to HIV/AIDS among secondary school \& college students and infected patients in the Indian context.

\section{Aim of the study}

This study aims to assess the impact of pharmacist-led counselling on HIV/AIDS among school \& college going students and infected patients in south India.

\section{Methods}

A cross-sectional survey was conducted for a period of four months (i.e., January to April 2014) at the SIMS group of Institutions (i.e., SIMS school, SIMS college of Pharmacy, SIMS college of physiotherapy, SIMS college of nursing, and SIMS college of life-sciences and at the Society of Welfare of HIV Infected People (SHIP) in Guntur district, Andhra Pradesh, India. The study was initiated after receiving the ethical approval from the Department of Pharmacy, Southern Institute of Medical Sciences (SIMS/IHEC/2013/01). The study population was comprised of school students i.e., class VIII, IX, and X (98 students), third \& final year students of Bachelor of Pharmacy (106 students), Physiotherapy (49 students), Nursing (98 students), \& Life sciences (111 students) and infected patients (47 patients) respectively. The school, college, and hospital authorities were informed, and verbal consent was obtained from them to conduct the study.

The survey was conducted in two settings. Setting-I comprises of the school and college students, whereas setting-II with the infected patients. Information was collected using a pre-designed, semi-structured questionnaire which is the same for the entire survey population (students \& patients). The questionnaire was validated for its content by the experts in the field (i.e., faculty members), and it was also tested on 40 school students, as a reliability measure (which were not included in the final analysis). The survey questionnaire was translated into the local language (i.e., Telugu) for the better understanding of the participants towards the disease. For the survey, the students were asked to gather at specified times other than class hours. The questionnaire contains various sections, and each section focused on different aspects of the disease such as knowledge of HIV/AIDS, knowledge on modes of transmission, methods of prevention, and knowledge about National Aids Control Organization (NACO), etc. The questionnaire was based on studies reported in Indian Journals. ${ }^{16,17}$ The participants who were present at the setting on the day of data collection were included in the study. All the subjects were explained about the study, and the verbal consent was taken before initiating the study. The study investigators (i.e., student pharmacists) explained the queries raised by the participants to ensure complete comprehension. The student pharmacist received the suitable education and training from the certified AIDS counsellors before initiating the study.

\subsection{Conceptual framework of the study}

The student pharmacists have developed a conceptual model Fig. 1 which depicts the process in which the study has been performed.

In addition, the student pharmacists provided the education to the enrolled patients about their infection, medications, nutrition, and lifestyle modifications complimented with suitably designed information leaflets. Patients were also counselled about the difference between being HIV positive and having AIDS, prevention, and management of opportunistic infections, etc. Also, psychological counselling was provided to reduce the stressors associated with HIV disease to the patients and their caregivers as well.

\section{Statistical analysis}

Each correct response was allotted with the score of 1 and wrong/ unmarked response was marked as 0. Data were entered into Microsoft

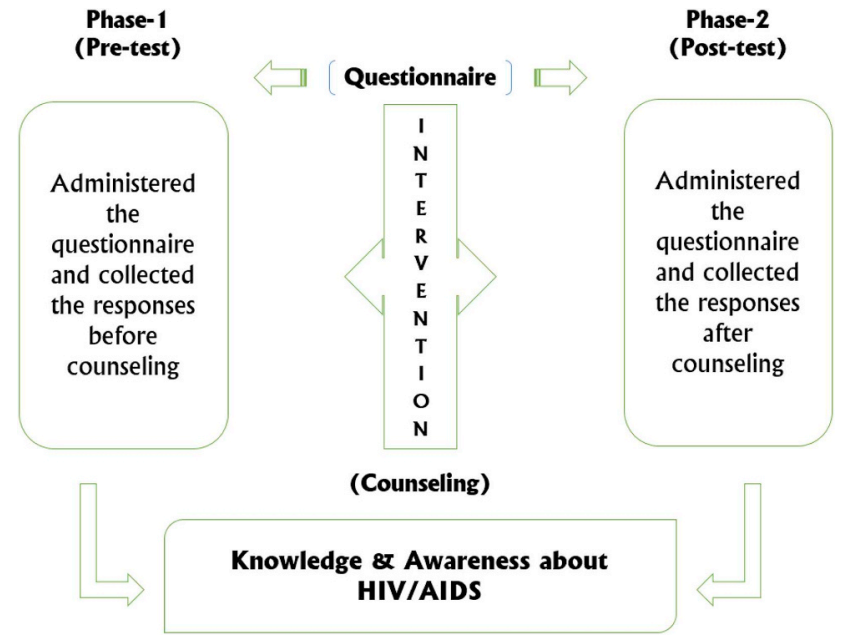

Fig. 1. A self-designed conceptual framework of the study.

Excel Spreadsheet and cross-checked for accuracy. Descriptive statistics on sample characteristics were computed, including means, standard deviation, and frequency distributions by using the SPSS statistics v16. $^{18}$

\section{Results and discussion}

Of the total 509 survey participants, 246 (48.3\%) were males, and $263(51.7 \%)$ were females with a mean age and SD of 24.59 years \pm 0.54 respectively. The gender distribution of the participants in this study is in contrast with the similar studies conducted by Oppong A.K et al., 2013, Prem kumar B et al., 2013, and O.M. Bankole et al., 2008 respectively. ${ }^{13,16,17}$ Detailed demographical information of the study participants was depicted in Table 1.

Among 509 study participants, 98 were school students, 364 were college students, and 47 were patients living with HIV/AIDS respectively. The gender-wide educational status of the participants in this study is in contrast with the similar study conducted by Prem kumar B et al., 2013. ${ }^{16}$ Detailed information on the educational status of the participants concerning the gender was depicted in Table 2 .

\subsection{Knowledge about HIV/AIDS: (Domain-I)}

Among the responses of questions related to knowledge about HIV/ AIDS before to counselling, only half of the school students (57.1\%) and one fourth $(23.4 \%)$ of the infected patients stated that they know the full-form of HIV/AIDS. Unfortunately, around two-thirds of the school students and more than $80 \%$ of the infected patients were not aware of the causative agent of AIDS. Almost one-third of the school students were not aware of the fact that HIV/AIDS could potentially weaken the body's immune system. Sadly, more than two-thirds of the school students and one-third of the college students were not aware that HIV/

Table 1

Demographic characteristics of the study participants.

\begin{tabular}{llll}
\hline Variables & School Students & College Students & Infected Patients \\
\hline $\begin{array}{l}\text { Number of } \\
\text { participants (n) }\end{array}$ & 98 & 364 & 47 \\
$\begin{array}{l}\text { Mean age } \pm \text { SD } \\
\text { Gender }\end{array}$ & $15.14 \pm 0.07$ & $22.65 \pm 0.19$ & $35.98 \pm 1.36$ \\
$\quad$ Males & $45(46 \%)$ & $169(46.4 \%)$ & $32(68 \%)$ \\
$\quad$ Females & $53(54 \%)$ & $195(53.6 \%)$ & $15(32 \%)$ \\
$\begin{array}{l}\text { Marital Status } \\
\text { Married }\end{array}$ & - & $49(13.5 \%)$ & $44(93.6 \%)$ \\
$\quad$ Unmarried & $98(100 \%)$ & $315(86.5 \%)$ & $3(6.4 \%)$ \\
\hline
\end{tabular}


Table 2

Categorization of gender-wide educational status of the study participants.

\begin{tabular}{|c|c|c|}
\hline \multirow[t]{2}{*}{ Educational Status } & \multicolumn{2}{|l|}{ Gender } \\
\hline & Males & Females \\
\hline \multicolumn{3}{|c|}{ School Students $(n=98)$} \\
\hline VIII standard $(\mathrm{n}=31)$ & 14 & 17 \\
\hline IX standard $(\mathrm{n}=28)$ & 12 & 16 \\
\hline $\mathrm{X}$ standard $(\mathrm{n}=39)$ & 19 & 20 \\
\hline \multicolumn{3}{|c|}{ College Students $(n=364)$} \\
\hline Pharmacy $(n=106)$ & 49 & 57 \\
\hline Physiotherapy $(\mathrm{n}=49)$ & 26 & 23 \\
\hline Nursing $(\mathrm{n}=98)$ & 43 & 55 \\
\hline Life-sciences $(n=111)$ & 51 & 60 \\
\hline \multicolumn{3}{|c|}{ Infected Patients $(n=47)$} \\
\hline Primary $(n=5)$ & 2 & 3 \\
\hline Secondary $(n=24)$ & 16 & 8 \\
\hline Uneducated ( $\mathrm{n}=18$ ) & 14 & 4 \\
\hline
\end{tabular}

AIDS patients could live without its symptoms. Unfortunately, more than half of the school students were not aware that HIV/AIDS could be diagnosed through a blood test and nearly one-third of them were not familiar with the symbol which represents HIV/AIDS (i.e., red ribbon). Astonishingly, more than $90 \%$ of the school students, more than half of the college students, and nearly half of the infected patients were not aware of the term NACO which is concerning. Interestingly, almost all the college students and infected patients positively responded to the fact that HIV/AIDS is dangerous. On overall basis, it is clearly observed that study participants, especially school students were not knowledgeable with regards to the HIV/AIDS. The responses of the study participants are in contrast with the studies conducted by Oppong A.K et al., 2013, and O.M. Bankole et al., 2008 respectively. ${ }^{13,17}$ While this study findings are similar with the studies conducted by Prem kumar B et al., 2013, ${ }^{16}$ and Gudi SK, 2018. ${ }^{19}$ The detailed information on responses regarding knowledge towards HIV/AIDS was depicted in Table 3.

\subsection{Knowledge about the mode of transmission: (Domain-II)}

Among the responses of questions related to knowledge about mode of transmission of HIV/AIDS before to counselling, more than onefourth of the school students were not aware that HIV/AIDS could be transmitted through blood transfusions, while more than half of the school students and infected patients stated that they were not familiar with the fact that HIV/AIDS could be transmitted from infected mother to child during pregnancy. Unfortunately, around two-thirds of the school students and one-fourth of the infected patients were not known that HIV/AIDS could be transmitted by sharing the needles and razors of the HIV positive individuals. Astonishingly, around half of the school students and infected patients have exhibited a misunderstanding that HIV/AIDS is an air-borne disease, while around one-fourth of the school students were thought that HIV/AIDS could be transmitted through insects. Interestingly, almost all the college students were familiar with all the questions related to the mode of transmission of HIV/AIDS. In a nutshell, it is evidently observed that study participants, especially school students \& infected patients were not well-known with the modes of transmission of the HIV/AIDS. The responses of the study participants are in contrast with the studies conducted by Oppong A.K et al., 2013, and O.M. Bankole et al., 2008 respectively. ${ }^{13,17}$ While this study findings are similar with the studies conducted by Premkumar B et al., 2013, ${ }^{16}$ and Gudi SK, 2018. ${ }^{19}$ The detailed information on responses regarding knowledge towards the mode of transmission of HIV/ AIDS was depicted in Table 3.

\subsection{Knowledge about prevention \& treatment: (Domain-III)}

Among the responses of questions related to knowledge about mode of transmission of HIV/AIDS before to counselling, more than onefourth of the school students were not familiar with the fact that AIDS has no cure, while around half of them were not aware that AIDS does not have a vaccine yet. Sadly, around two-thirds and about $90 \%$ of the school students were not knowledgeable that usage of safety measures like condoms and practicing monogamy could potentially prevent the

Table 3

Summary of responses towards awareness of HIV/AIDS among the study participants.

\begin{tabular}{|c|c|c|c|c|c|c|c|}
\hline \multirow[t]{2}{*}{ Sl. No. } & \multirow[t]{2}{*}{ Domains } & \multicolumn{2}{|c|}{ School Students (correct responses) } & \multicolumn{2}{|c|}{ College Students (correct responses) } & \multicolumn{2}{|c|}{ Infected Patients (correct responses) } \\
\hline & & B.C & A.C & B.C & A.C & B.C & A.C \\
\hline I & Knowledge about HIV/AIDS & & & & & & \\
\hline 1 & Do you know the full form of HIV/AIDS? & $56(57.1 \%)$ & $91(92.8 \%)$ & $362(99.4 \%)$ & $364(100 \%)$ & $11(23.4 \%)$ & $42(89.3 \%)$ \\
\hline 2 & HIV is the causative agent for AIDS? & $37(37.7 \%)$ & $85(86.7 \%)$ & $349(95.8 \%)$ & $363(99.7 \%)$ & $09(19.1 \%)$ & $38(80.8 \%)$ \\
\hline 3 & Does HIV/AIDS weaken body's immune system? & $62(63.2 \%)$ & $93(94.8 \%)$ & $361(99.1 \%)$ & $364(100 \%)$ & $41(87.2 \%)$ & $47(100 \%)$ \\
\hline 4 & Do you think HIV/AIDS is dangerous? & $79(80.6 \%)$ & $98(100 \%)$ & $364(100 \%)$ & $364(100 \%)$ & $47(100 \%)$ & $47(100 \%)$ \\
\hline 5 & Can HIV/AIDS patients live without its symptoms? & $21(21.4 \%)$ & $75(76.5 \%)$ & $249(68.4 \%)$ & $359(98.6 \%)$ & $39(82.9 \%)$ & $46(97.8 \%)$ \\
\hline 6 & Can HIV/AIDS be confirmed through blood test? & $44(44.8 \%)$ & $96(97.9 \%)$ & $346(95 \%)$ & $362(99.4 \%)$ & $41(87.2 \%)$ & $47(100 \%)$ \\
\hline 7 & Is red-ribbon a symbol of HIV/AIDS awareness? & $64(65.3 \%)$ & $97(98.9 \%)$ & $323(88.7 \%)$ & $364(100 \%)$ & $43(91.4 \%)$ & $47(100 \%)$ \\
\hline 8 & Have you ever heard about NACO? & $09(9.1 \%)$ & $92(93.8 \%)$ & $162(44.5 \%)$ & $361(99.1 \%)$ & $26(55.3 \%)$ & $46(97.8 \%)$ \\
\hline II & Knowledge about mode of transmission & & & & & & \\
\hline 1 & Can HIV/AIDS be transmitted through sex? & $81(82.6 \%)$ & $98(100 \%)$ & $364(100 \%)$ & $364(100 \%)$ & $46(97.8 \%)$ & $47(100 \%)$ \\
\hline 2 & $\begin{array}{l}\text { Can HIV/AIDS be transmitted through blood } \\
\text { transfusion? }\end{array}$ & $68(69.3 \%)$ & $97(98.9 \%)$ & $357(98 \%)$ & $364(100 \%)$ & $38(80.8 \%)$ & $46(97.8 \%)$ \\
\hline 3 & $\begin{array}{l}\text { Can HIV/AIDS be transmitted from mother to child } \\
\text { during pregnancy? }\end{array}$ & $42(42.8 \%)$ & $94(95.9 \%)$ & $359(98.6 \%)$ & $363(99.7 \%)$ & $21(44.6 \%)$ & $45(95.7 \%)$ \\
\hline 4 & Can HIV/AIDS be transmitted by sharing needles? & $34(34.6 \%)$ & $91(92.8 \%)$ & $355(97.5 \%)$ & $364(100 \%)$ & $36(76.5 \%)$ & $45(95.7 \%)$ \\
\hline 5 & Is HIV/AIDS an air-borne disease? & $47(47.9 \%)$ & $89(90.8 \%)$ & $349(95.8 \%)$ & $361(99.1 \%)$ & $27(57.4 \%)$ & $43(91.4 \%)$ \\
\hline 6 & Can HIV/AIDS be transmitted through insects? & $75(76.5 \%)$ & $96(97.9 \%)$ & $362(99.4 \%)$ & $364(100 \%)$ & $39(82.9 \%)$ & $47(100 \%)$ \\
\hline 7 & $\begin{array}{l}\text { Can HIV/AIDS be transmitted by sharing food, } \\
\text { clothes and utensils? }\end{array}$ & $79(80.6 \%)$ & $98(100 \%)$ & $351(96.4 \%)$ & $362(99.4 \%)$ & $45(95.7 \%)$ & $47(100 \%)$ \\
\hline III & Knowledge about prevention \& treatment & & & & & & \\
\hline 1 & Can AIDS be cured? & $72(73.4 \%)$ & $98(100 \%)$ & $359(98.6 \%)$ & $364(100 \%)$ & $46(97.8 \%)$ & $47(100 \%)$ \\
\hline 2 & Is there a vaccine for AIDS? & $56(57.1 \%)$ & $92(93.8 \%)$ & $335(92 \%)$ & $364(100 \%)$ & $42(89.3 \%)$ & $47(100 \%)$ \\
\hline 3 & Can use of condom reduce the risk of HIV/AIDS? & $35(35.7 \%)$ & $96(97.9 \%)$ & $351(96.4 \%)$ & $364(100 \%)$ & $46(97.8 \%)$ & $47(100 \%)$ \\
\hline 4 & Can monogamy prevent HIV/AIDS? & $12(12.2 \%)$ & $89(90.8 \%)$ & $343(94.2 \%)$ & $359(98.6 \%)$ & $45(95.7 \%)$ & 47 (100\%) \\
\hline
\end{tabular}

*B.C - Before Counselling.

A.C - After Counselling. 
risk of getting HIV/AIDS respectively. Fortunately, almost all the college students and infected patients were apprehensive regarding all the questions in this domain. On overall grounds, it is noticed that the study participants, especially school students were not conscious about the preventive measures and treatment options of the HIV/AIDS. The responses of the study participants are in contrast with the studies conducted by Oppong A.K et al., 2013, and O.M. Bankole et al., 2008 respectively. ${ }^{13,17}$ While this study findings are similar with the studies conducted by Premkumar B et al., 2013, ${ }^{16}$ and Gudi SK, 2018. ${ }^{19}$ The detailed information on responses regarding knowledge towards prevention \& treatment of HIV/AIDS was depicted in Table 3.

In a study conducted in India by Chandrasekhar Reddy Bolla et al., 2013 , has stated that only $42.83 \%, 31.34 \%$, and $33.39 \%$ of the study participants knew how to prevent HIV/AIDS, HIV/AIDS cannot be transmitted through the mosquito bites, and intravenous drug abuse could spread HIV virus respectively. ${ }^{20}$ While, in another study conducted by Puneet Sandhu et al., 2015, in India has inferred that there exists a major misconception about the transmission of HIV/AIDS through a mosquito bite and touching. And revealed that $47.5 \%$ females and only $25 \%$ of males were aware about usage of disposable needles and syringes. ${ }^{21}$

The role of pharmacist towards HIV/AIDS goes beyond the counselling to adherence monitoring. The pharmacist can be a valuable part of the patient care team by providing medication review and patient education for HIV/AIDS. ${ }^{22}$ Education has an impact on awareness and pharmacist caring for HIV/AIDS patients in the hospital, community, and other ambulatory settings have an important opportunity to affect patient outcomes in terms of both morbidity and mortality positively. ${ }^{23}$

\section{Conclusion}

This study is unique of its kind which has provided with the basic essence of the impact of pharmacist counselling among students and patients towards HIV/AIDS. This study adds on to the existing evidence by strengthening the fact that students, as well as patients, still are not well-known with HIV/AIDS. Although most of the college students have shown the promising results, there is an immense need for health education and prevention awareness camps for HIV/AIDS in south India. However, further extensive and rigorous studies addressing this research question are needed to eradicate AIDS and to diminish the stigma associated with it among the public in south India.

\section{Limitations}

The only limitation of this study would be the generalizability of its results to the entire country, as the study was conducted and thus restricted to only south India.

\section{Conflicts of interest}

There are no conflicts of interests.

\section{Ethical approval}

The study was approved by the institutional ethics committee.

\section{Funding}

No funding sources.

\section{Acknowledgment}

Authors explicit sincere gratitude to all the students of SIMS group of Institutions and patients of SHIP for allotting their time and support to conduct this study.

\section{Appendix A. Supplementary data}

Supplementary data to this article can be found online at https:// doi.org/10.1016/j.cegh.2019.01.006.

\section{References}

1. Wallace/Maxcy- Rosenau-Last. Text book of public health and preventive medicine. The Epidemiology and Prevention of Human Immunodeficiency Virus (HIV) Infection and Acquired Immunodeficiency Syndrome (AIDS). fifteenth ed. Mc Graw Hill; 2008:189 (Chapter 11).

2. Park K. Park's text book of preventive and social medicine. (Chapter 5). Epidemiology of Communicable Diseases: AIDS. twenty-first ed. Jabalpur: M/s Banarsidas Bhanot; 2011:316-329.

3. Popovic M, Sarngadharan MG, Read E, Gallo RC. Detection, isolation, and continuous production of cytopathic retroviruses (HTLV-III) from patients with AIDS and preAIDS. Science. 1984;224:497-500.

4. Baldo M. Peer education: a successful strategy with some constraints. Sex Health Exchange. 1998(4):1-3.

5. Goldman DA, Weinstein RA, Wenzel RP. Strategies to prevent and control the emergence of antimicrobial resistant micro-organisms in hospital. J Am Med Assoc. 1996;275:234-249.

6. UNAIDS. AIDSinfo. 2018; 2018 (accessed September 2018).

7. Appiah-Agyekum NN, Suapim RH. Knowledge and awareness of HIV/AIDS among high school girls in Ghana. HIV/AIDS (Auckland, NZ). vol. 5. 2013; 2013:137-144.

8. Samkange-Zeeb FN, Spallek L, Zeeb H. Awareness and knowledge of sexually transmitted diseases (STDs) among school-going adolescents in Europe: a systematic review of published literature. BMC Public Health. 2011;11:727.

9. Persson E, Sandströäm B, Jarlbro G. Sources of information, experiences and opinions on sexuality, contraception and STD protection among young Swedish students. Adv Contracept. 1992;8:41-49.

10. Sachsenweger M, Kundt G, Hauk G, et al. Knowledge of school pupils about the HIV/ AIDS topic at selected schools in Mecklenburg-Pomerania: results of a survey of school pupils. Gesundheitswesen. 2011;73(1):e21-e26. https://doi.org/10.1055/s0029-1246199.

11. Editorial Team. Young people's knowledge of sexually transmitted infections and condom use surveyed in England. Euro Surveill. 2005;10(31) pii = 2766, Accessed date: 30 November 2010 .

12. Ethier KA, Dittus PJ, DeRosa CJ, et al. School-based health center access, reproductive health care, and contraceptive use among sexually experienced high school students. J Adolesc Health. 2011;48:562-565.

13. Oppong Asante K, Oti-Boadi M. HIV/AIDS knowledge among undergraduate university students: implications for health education programs in Ghana. Afr Health Sci. 2013;13(2):270-277

14. Siegel D, Krasnovsky F, Durbin M, Chesney M, Lazarus N. AIDS knowledge, attitudes, and behavior among inner city, junior high school students. J Sch Health. 1991;61:160-165.

15. Bachani D, Sogarwal R. National response to HIV/AIDS in India. Indian J Community Med. 2010;35(4):469-472.

16. Premkumar B, Gayathri T, Ravichandran S. HIV/AIDS awareness, attitude and perception among school, college students and hospital workers. Indian J Pharm Pract. 2013;6(2):42-48.

17. Bankole OM, Mabekoje OO. Awareness and opinions about HIV/AIDS among secondary school teachers in Ogun State, Nigeria. Sci Res Essays. 2008;3(6):245-253

18. SPSS Inc. SPSS for Windows, Version 16.0. Released Chicago: SPSS Inc; 2007.

19. Gudi SK. Assessment of knowledge, attitude and perceptions of HIV/AIDS among secondary school students in Guntur district of south India: a cross-sectional survey. Int J Sci Rep. 2018;4(4):87-92.

20. Reddy Bolla Chandrasekhar, et al. Knowledge regarding HIV/AIDS among secondary school students in Khammam town, Andhra Pradesh. Int J Res Dev Health. 2013;1(3):103-108.

21. Sandhu Puneet, et al. Awareness and knowledge about HIV/AIDS among panjab university students. Int J E Plann Res. 2015;4(2):63-66.

22. Cocohoba JM, Althoff KN, Cohen M, et al. Pharmacist counseling in a cohort of women with HIV and women at risk for HIV. Patient Prefer Adherence. 2012;6:457-463.

23. Saberi P, Dong BJ, Johnson MO, Greenblatt RM, Cocohoba JM. The impact of HIV clinical pharmacists on HIV treatment outcomes: a systematic review. Patient Prefer Adherence. 2012;6:297-322. https://doi.org/10.2147/PPA.S30244. 